\title{
DAKWAH KULTURAL MUHAMMADIYAH ANTARA PEMBARUAN DAN PEMBAURAN
}

\author{
Suparto \\ Fakultas Dakwah dan Komunikasi Universitas Islam Negeri Syarif Hidayatullah Jakarta. e-mail: Suparto05@ \\ yahoo.co.uk
}

Abstract

Muhammadiyah has long been recognized as a movement of dakwah (Islamic promulgation), tajdid (religious renewal), and social empowerment, and has been recorded by the history as the point of departure toward the resurrection of Muslim community in Indonesia. A dakwah activity with a social touch through educational efforts and social services has made this organization as an icon of a distinct Islamic modernization. Due to the increasing challenges faced by the dakwah activity, Muhammadiyah has to dovetail its movement with the sensitivity of cultural rooms located in the heart of Indonesian communities. Therefore, in this modern juncture, Muhammadiyah cannot be conceived as a movement without cultural sensitivity; a movement that tends to banish local cultural elements. This necessitates Muhammadiyah to acknowledge a spotlight where cultures have been well flourishing in such a colorful country.

Key words: muhammadiyah, dakwah culture, modernizations 


\section{Pendahuluan}

Muhammadiyah dan Rasionalisasi Dakwah Secara umum label sebagai gerakan Islam, gerakan dakwah, dan gerakan tajdid memang sangat lekat dengan watak dan ciri utama Muhammadiyah (Mulkhan, 1990: 65). Di samping itu gerakan ini dipandang sebagai gerakan modern karena mampu menggunakan arus organisasi, bukan mitologi individual, sebagai wahana kegiatan dan eksistensinya (Damami, 2000: 35). Sehingga, tidaklah mengherankan bahwa kemunculan Muhammadiyah sempat menyergap kekaguman. Seorang pakar antropologi dari University of North Carolina, Chapel Hill. Pasalnya, di antara tiga negara Asia Tenggara, yakni Malaysia, Singapura, dan Indonesia, yang menjadi lahan penelitiannya, hanya Indonesia sajalah yang memiliki organisasi reformis yang memiliki peranan yang cukup besar hingga dewasa ini, yaitu Muhammadiyah.

Muhammadiyah merupakan satu-satunya gerakan reformis Islam yang paling kokoh yang pernah mengukir sejarah Asia Tenggara, bahkan boleh dikatakan satu-satunya gerakan reformis Islam yang paling stabil yang ada di muka bumi ini. Kekaguman Peacock bukan tanpa alasan karena memang kelahiran Muhammadiyah di Yogyakarta merupakan peristiwa besar dimana gerakan purifikasi reformis ini mampu menggeliat secara progresif dari dalam tembok peradaban Jawa yang sangat sinkretik, yakni Yogyakarta dan kesultanannya yang merupakan refleksi peninggalan kerajaan Mataram kuna. Lebih mengherankan lagi adalah kenyataan bahwa kebanyakan orang Yogya adalah pendukung setia Muhammadiyah, sedangkan pendukung santri kolot (istilah yang dipakai oleh Peacock untuk merujuk pada kelompok tradisional) tidak begitu signifikan dan hanya berkisar di daerah Krapyak saja (Peacock, 1978: 24). Jawa memang dikenal sinkretis oleh para ahli dibanding daerah lainnya di Indonesia, semisal Aceh, Minangkabau, dan Banten, sebagaimana dikatakan oleh Benda:

"Only in those parts of Indonesia which had been at least affected by Hindu civilization in past centuries-such as Acheh and Minangkabau region in Sumatra and Banten in West Java, -did Islam almost from the outset profoundly affect the religious, social and political consciousness of its adherents. Thus 
it is in those regions that the new faith has manifested itself in a purer, less conciliatory and at times even aggressive form. In the greater parts of Java, on the other hand Islam had been forced to adopt itself to centuries old traditions, partly indigenous, partly Hindu-Buddhist, and in the process to lose much of its doctrinal rigidity" (Benda, 1958: 28).

Melalui penerjemahan ulang pesan-pesan suci agama ke dalam tataran praxis-empiris yang mapan, Muhammadiyah berusaha mengikis kemunduran dan keterbelakangan umat Islam dalam berbagai segi. Gerakan tajdid yang disuarakan Muhammadiyah merupakan langkah signifikan untuk mendobrak kejumudan berfikir masyarakat Islam Indonesia yang cenderung terperangkap oleh kerangkeng absolut doktrin dogmatik.

Gerakan Muhammadiyah yang lebih menampakkan aksi nyata melalui pendidikan dan gerakan sosial merupakan fenomena yang secara signifikan mampu mematahkan tesis Donald Eugene Smith (1970: 2) yang secara serampangan menyimpulkan bahwa "secara umum dan benar, agama dipandang sebagai penjegal proses modernisasi." Sebaliknya Muhammadiyah membuktikan bahwa pembaruan dan penyegaran kembali pemahaman agama dapat menjadi pendorong ke arah modernitas dan kemajuan umat. Umat didorong untuk maju dan meninggalkan aras kejumudan yang sangat kental pada saat itu. Pemahaman kembali agama diupayakan agar kesadaran umat Islam tergugah bahwa agama bukan saja dipahami sebagai pengetahuan tentang nasihat-nasihat Nabi dan doktrin-doktrin suci Tuhan, akan tetapi agama dapat dipahami melalui penuangan pesan-pesan Tuhan ke dalam realitas keseharian yang praksis sebagai pemahaman agama yang sesungguhnya. Harus dimengerti bahwa revivalisme Islam bukanlah merupakan usaha untuk membangun kembali komunitas Islam awal masa kejayaan Nabi dalam maknanya yang literal dan kaku. Bukan pula sebagai usaha untuk memaksakan aplikasi al Quran dan al Sunah secara skriptural berbasis pada romantisme kesejarahan terhadap kondisi kekinian yang nyata-nyata berbeda dan lebih kompleks (Esposito, 1998: 57). Lebih dari itu adopsi kekinian dan akomodasi modernitas adalah sebuah keniscayaan yang harus diemban Muhammadiyah ketika mencoba mengusung agenda baru perubahan umat.

Jalan yang dilalui oleh Muhammadiyah menuju tradisi Islam yang sinoptik 
dan sistematik agaknya harus melalui proses fungsionalisasi (functionalisation) sebagai jembatan untuk membangun umat. Kemunculan Muhammadiyah di Indonesia dapat dipandang sebagai keberlanjutan proses Islamisasi masyarakat Indonesia; Islamisasi merupakan proses yang berkesinambungan hingga kini (ongoing process) (Nakamura, 1983: 1-3). Fungsionalisasi dapat dipahami sebagai "proses penerjemahan di mana karya intelektual dari sebuah diskursus menjadi perantara strategis yang menjembatani diskursus lainnya” (Starrett, 1998: 9). Penerjemahan tersebut tidak saja menempatkan sebuah karya intelektual, dalam hal ini pesan-pesan agamis, pada lahan baru, namun secara radikal mampu menyesuaikan ranah tekstual pada kontekstual kekinian. Dalam konteks ini, koreksi Muhammadiyah atas kejumudan yang melanda masyarakat Islam adalah dengan cara mendobrak kemapanan religius dengan ide membangkitkan kembali ijtihad. Ide ini kemudian menjadi batu loncatan (stepping stone) menuju masyarakat Islam yang kritis dalam menelaah dan mengamalkan ajaran-ajaran agamanya pada tataran yang lebih luas, yang mencakup ranah sosial, budaya dan ekonomi masyarakat Islam masa itu. Pada awalnya gerakan ini berwatak agama, namun kemudian berkembang menjadi gerakan yang menyentuh aspek duniawiah. Peran Muhammadiyah melalui empat ranah praksis yang meliputi pembaruan agama, perubahan sosial, kekuatan politik, dan pembendung Kristenisasi (Shihab, 1998: xv-xxxi).

Gerakan dakwah Muhammadiyah yang bermuatan fungsionalisasi tidak akan terdengar gaungnya jika tidak beralaskan pada proses rasionalisasi sebagai ruh gerakan modern. Adapun proses rasionalisasi atau penalaran makna ini digunakan untuk memformulasikan solusi yang tepat bagi permasalahan yang dihadapi umat Islam kini dan masa depan. Hal ini sejalan dengan pendapat Weber yang memandang bahwa sejarah manusia terus melaju menuju stadium rasionalisasi. Rasionalisasi kemudian berbuah menjadi aksi yang secara effesien dan metodis dijadikan sarana untuk menggapai segala tujuan yang ditentukan oleh manusia itu sendiri (Peacock, 1978:2).

Weber memandang bahwa aksi apapun akan terasa hampa bagi para aktor yang terlibat di dalamnya jika tidak menghasilkan perubahan spiritual (spiritual changes) yang mampu mendorong kepada pencapaian tujuan secara 
tepat. Reformasi pemahaman agama di kalangan denominasi Calvinis pada abad ke-16 dan ke-17 ternyata mengilhami penggunaan pesan-pesan suci agama untuk mendorong kreativitas manusia merengkuh kehidupan duniawiah yang kapitalis (Weber, 1958: 79). Prinsip utama dalam metodologi Weber adalah verstehen atau interpretative understanding (pemahaman interpretatif) yang meniscayakan bahwa sang aktor mampu memahami dan menyadari makna dari segala tindakannya (Peacock, 1978: 2). Dengan kata lain aksi sosial (social action atau sociales Handeln) bukan hanya dipahami sebatas tingkah laku an sich. Lebih dari itu tingkah laku tersebut harus dipandang juga sebagai pola yang sarat makna. Secara sederhana bisa dikatakan bahwa aktor yang melakukan aksi sosial harus memahami apa yang dia lakukan dan tujuan yang hendak dicapai dari aksinya itu. Rasionalisasi pesan-pesan religius agaknya juga dipicu oleh ide-ide yang berasal dari luar terutama gejolak yang terjadi di Mekah dan Kairo yang getar gelombangnya turut menghentak kesadaran KH Ahmad Dahlan (1868-1923) untuk berbuat sesuatu dalam kegiatan dakwahnya. Dalam hal ini Deliar Noer menyatakan:

"...they had partly been inspired by development and ideas from elsewhere, especially the Middle East, and in particular Mecca and Cairo, which with their publication and institution of higher learning, had served as centres for Islamic studies..." (Noer, 1973: 296).

KH. Ahmad Dahlan terpengaruh oleh buah pikiran Muhammad Abduh (1849-1905) yang pro-perubahan. Hal ini diperkuat oleh kenyataan bahwa KH Ahmad Dahlan pernah bertemu dan berdiskusi dengan Rasyid Ridha (1865-1930), murid Abduh, di Mekah (Hadikusuma: 66). KH Ahmad Dahlan juga memperkaya wacana pengembangan umat melalui tulisan-tulisan Abduh dan Ridla dalam jurnal al Manar yang diterbitkan oleh Abduh dan Rasyid Ridha. Secara kreatif KH Ahmad Dahlan juga menerjamahkan sebagian ideide mereka ke dalam bahasa Jawa agar diketahui oleh umum (Ali, 1971: 48).

Sebagai penyambung semangat perubahan yang diusung oleh Jamaluddin al Afghani (1838-1897), Muhammad Abduh memandang bahwa upaya transformatif untuk menciptakan keunggulan umat Islam bisa dilaksanakan melalui penafsiran ulang doktrin-doktrin Islam dan implementasinya melalui 
pendidikan nasional dan reformasi sosial. Kemudian ide-ide progresifnya ia tuangkan dalam jurnal al-Manar (1898) bersama dengan Rasyid Ridha. Abduh meyakini bahwa kemunduran umat Islam lebih disebabkan oleh pasivitas dan fatalisme kaum Sufi dan pandangan yang kaku di kalangan ulama tradisional yang menghalangi penafsiran ulang atas ajaran agama yang lebih segar.Abduh juga sangat mengecam tradisi taklid yang berkembang saat itu dan menawarkan pandangan teologis baru untuk membangun umat (Esposito, 1998: 131).

Teologi yang dikembangkan Abduh terkenal dengan nama Theology of Unity (teologi tauhid) karena Abduh sangat meyakini bahwa Tuhan menciptakan wahyu sebagai pilar utama agama Islam, sedangkan kapasitas rasional dan intelektual tetap dibutuhkan untuk mengejawantahkan manifestasi alam ini atau dengan istilah Jawa" mahayu hayuning bawana" (mempercantik cantiknya alam maya) (Abduh, 1966: 78). Bahkan dalam salah satu edisinya, al Manar pernah melontarkan kritik pedas terhadap para pelajar yang belajar di Timur Tengah yang hanya membawa sedikit pengetahuan Islam dan menjadi gagap ketika berhadapan dengan abad modern karena pengaruh para syaikh yang gagal mengajarkan Islam yang sesungguhnya (Abaza, 1994: 59).

Dakwah KH Ahmad Dahlan bukan sekedar dakwah verbal (bi al lisan) akan tetapi dakwah dengan amalan praksis (bi al hal). Umpamanya saja, gerakan amal Muhammadiyah yang terinspirasi oleh konteks surah al Ma'un. Surah ini mendasari dibentuknya amal usaha Muhammadiyah di bidang kesejahteraan sosial, yakni dengan didirikannya PKO (Penolong Kesengsaraan Oemoem) pada tahun 1918. Surah tersebut berisi tentang perilaku keagamaan yang tidak filantropik dan kesalehan sosial yang harus diemban seseorang yang beragama dalam kaitannya dengan tanggung jawab sosial. Di sinilah semangat Muhammadiyah dijabarkan melalui rasionalisasi dakwah sebagai upaya penerjemahan ulang terhadap kebekuan dan kekeringan fungsi agama dalam kehidupan nyata. Agama tidak hanya berputar pada arena ritual, namun agama dipandang sebagai tanggung jawab sosial dan praktek sosial. 


\section{Dakwah Kultural Menanggapi Konteks Kekinian}

Peta masyarakat dunia pasca perang dingin bukan lagi didasarkan pada domain ideologi, politik, maupun ekonomi. Namun masyarakat dunia terpetakan oleh warna budayanya. Sehingga manusia dan bangsa-bangsa di dunia ini berusaha mencari jawaban atas pertanyaan yang paling mendasar yang selalu menghinggapi alam pikiran manusia, yakni who are we? (Siapakah kita) (Huntington, 1992: 21). Islam sebagai sistem budaya merupakan unsur yang bersifat transnasional, transkultural, dan transetnik dalam wacana umat yang tunggal (ummah wahidah). Oleh karena itu pemahaman multikulturalisme dan pluralisme dalam lanskap sosial keindonesiaan merupakan keharusan bagi Muhammadiyah dalam menghadapi gerusan zaman dan tantangan mondial keumatan. Jika pada awal kemunculannya Muhammadiyah dikenal sebagai gerakan purifikasi agama dan pembendung arus kristenisasi (Kerstening Politiek) masa kolonial maka pada saat sekarang ini Muhammadiyah harus dapat menyadari posisinya di tengah pluralitas kultural melalui, minimal, dua cara pandang (Shihab, 1965: 115):

Pertama, hubungan dengan organisasi keislaman lain harus dibina tanpa harus ada rasa curiga dan stereotyping yang berpotensi semakin menggali jurang fragmentasi sosial. Organisasi keislman tidak terbatas pada organisasi lokal, namun juga organisasi nasional dan internasional. Sayangnya, seringkali realitas di lapangan membuktikan bahwa tidak sedikit Muhammadiyah yang sering bersikap antagonis terhadap ekspresi kultural masyarakat tempatan. Pembid'ahan pada produk kultur tempatan membuat gerak Muhammadiyah tidak leluasa. Alih-alih membangun soliditas keumatan, Muhammadiyah malah terpuruk dalam "perang agama melawan agama", meminjam istilah Syari'ati. Tidak sepatutnya benturan budaya menjadikan Muhammadiyah lupa akan masalah keumatan yang lebih serius dan lebih penting untuk ditangani. Padahal al Quran sendiri menyatakan:

"Hai orang-orang yang beriman, janganlah kamu mengolok-olok kaum yang lain, boleh jadi mereka yang diolok-olok lebih baik dari mereka yang mengolok-olok dan jangan pula kaum perempuan mengolok-olok kaum perempuan lainnya, boleh jadi kaum perempuan yang diolok-olok lebih baik dari kaum perempuan yang mengolok-olok..." (QS al Hujurat (49): 11). 
Dalam ayat lain, Allah berfirman:

"Hai manusia, sesungguhnya Kami menciptakan kamu dari seorang laki-laki dan seorang perempuan, kemudian menjadikan kamu berbangsa-bangsa dan bersuku-suku supaya kamu saling mengenal. Sesungguhnya orang yang paling mulia di sisi Allah adalah orang yang paling bertakwa di antaramu. Sesungguhnya Allah Maha Mengetahui dan Maha Mengenal" (QS al Hujurat: 12).

Mengenal dalam ayat ini bukan hanya bermakna mengetahui permukaan saja, namun lebih dari itu mengenal mengandung makna adanya pertukaran ide dan paham serta keterbukaan yang dewasa terhadap kandungan substantif pemikiran dan paham lain.

Kedua, menggagas kerjasama dengan kelompok non-Muslim adalah suatu keharusan sebagai bukti kesadaran Muhammadiyah yang eksistensinya berada di tengah-tengah lintas peradaban dan ideologi yang plural. Dialog antar iman dan kerjasama konkrit bisa menjadi perantara yang efektif bagi Muhammadiyah untuk berjalan berdampingan dengan kelompok lain. Jika Muhammadiyah dulu sebagai pesaing gerakan Kristenisasi kolonial, maka saat ini Muhammadiyah harus bisa lebih terbuka memahami realitas kemajemukan ini. Dalam hal ini al Quran menyatakan:

"Katakanlah: 'Kami beriman kepada Allah dan kepada apa yang diturunkan kepada kami dan diturunkan kepada Ibrahim, Ismail, Ishaq, Yaqub, dan anakanaknya, dan apa yang diberikan kepada Musa, Isa, dan para nabi dari Tuhan mereka'. Kami tidak membedakan-bedakan seorang pun diantara mereka dan hanya kepada-Nya lah kami menyerahkan diri" (QS ali Imron: 84).

Membangun dialog dengan kelompok non-Muslim akan semakin mendorong Muhammadiyah untuk menampilkan Islam sebagai rahmat alam semesta sekaligus meningkatkan posisi tawar Muhammadiyah sebagai organisasi besar.

Cara pandang pertama diharapkan mampu menciptakan sinergitas dan kohesitas antar organisasi Islam Indonesia dalam meramu solusi atas berbagai persoalan umat. Pemberdayaan organisasi Islam lebih difokuskan kepada sebarapa jauh kontribusi mereka terhadap pemberantasan kemiskinan, pengangguran, kebodohan, keterbelakangan, dan berbagai persoalan sosial 
lainnya. Gerakan-gerakan Islam sempalan kemungkinan besar terjadi akibat "melempemnya" organisasi Islam Indonesia menyoal masalah-masalah krusial keumatan karena terlena pada urusan internal dan debat fikihisme disamping politisasi agama atas nama pembangunan. Membangun kerjasama dengan organisasi Islam lainnya juga bisa dipahami sebagai semakin intensifnya Muhammadiyah membangun jejaring dengan organisasi-organisasi Islam antar bangsa. Di samping itu, hal ini juga mengindikasikan agar Muhammadiyah semakin sensitif dan dewasa atas keberagaman sosiokultural masyarakat Islam nasional maupun internasional. Adapun cara pandang kedua dapat mendorong upaya dialog antar agama yang lebih praksis untuk menghadapi masalah-masalah kemanusiaan dunia. Muhammadiyah dapat berkontribusi untuk menawarkan pendekatan teologis universal yang dapat menawarkan solusi atas problema kemanusiaan yang dihadapi bangsa-bangsa dunia. Modernitas dan globalitas tidak menyebabkan agama kehilangan perannya dalam kehidupan dan lanskap sosial (Beyer, 1994: 225). Bahkan agama dapat digunakan sebagai gerakan pembebas yang mereviltasisasi ajaran teologis dalam ranah yang lebih nyata.

\section{Pentingnya Dakwah Kultural}

Menepis rasa curiga dan mengungkit gairah untuk membangun persahabatan kultural dan keharmonisan sosial dalam tubuh umat Islam adalah sebuah kemutlakan untuk menciptakan nuansa harmonis dalam atmosfere kehidupan individu dan sosial. Karena keharmonisan itu sendiri pada hakikatnya merupakan perwujudan kehendak manusia dan kehendak Tuhan, sebagaimana Professor Khurshed Ahmed (Choudhury, 1993: 3) berpendapat :

"Islam stands for a commitment to surrender one's will to the will of God and thus to be at peace with the Creator and with all the has been created by Him. It is through submission to the will of God that peace is brought about. Harmonization of man's will with the will of God leads to the harmonization of different spheres of life under an all-embracing ideal".

Mawdudi mengamati bahwa Iman merupakan pola hubungan 
antara hamba dan Tuhan yang harus didasarkan pada akal dan kemauan. Sehingga bagi siapa saja yang memasrahkan diri kepada Allah, maka ia seharusnya mampu berbaur dengan anggota-anggota masyarakat lainnya. Melalui pembauran inilah, seyogyanya, bangunan masyarakat Muslim dan masyarakat sosial dapat ditata dengan indah. Bagi Mawdudi masyarakat Islam adalah masyarakat ideologis yang sama sekali berbeda dengan masyarakat lain yang biasanya diikat oleh sekatan suku, warna kulit dan wilayah (Choudhury, 1993: 5). Di sinilah kekuatan ideologi Islam yang menembus sekat-sekat suku, budaya, dan geografis. Kesadaran inilah yang harus menjadi sifat Muhammadiyah, yakni memperbanyak kawan dan mengamalkan spirit ukhuwah, keagamaan dan kemasyarakatan, serta kerjasama dengan golongan Islam manapun juga dalam usaha menyiarkan dan mengamalkan agama Islam serta membela kepentingannya (Mulkhan, 1999a: 53).

Dakwah kultural Muhammadiyah dimaksudkan sebagai upaya untuk memahami dan menggunakan potensi-potensi kultural masyarakat Islam sebagai wahana untuk menanamkan Islam yang membumi, yakni Islam yang bisa merubah potensi menjadi gerak kemajuan sosial. Dakwah kultural meniscayakan adanya usaha pembauran dengan kelompok lain tanpa harus dihantui perasaan hipokritikal dan mengangkangi kesetiaan terhadap "akidah" Muhammadiyah. Namun dakwah kultural dimaksudkan untuk membangun nuansa harmonis dengan mozaik bangunan budaya kelompok lain. Semangat Islam adalah semangat substantif yang lebih mementingkan isi dibanding wadah. Sebagaimana Islam dapat diekspresikan melalui berbagai wahana dan simbol. Dakwah kultural merupakan upaya pengislaman (Islamisasi) masyarakat Indonesia. Karena sangat disadari bahwa proses pengislaman di Indonesia adalah proses yang belum berhenti, sebagaimana pandangan C.W.J. Drewes (1955) (Osman, 1997: xxix):

"The Islamization of Indonesia is still in progress, not only in the sense that Islam is still spreading among pagan tribes, but also in that peoples who went over to Islam centuries ago are living up was almost to the standard of Muslim orthodox ... as the Indonesians grew better acquainted with the religious literature of Islam, the dividing line not only between orthodoxy and heterodoxy but also 
between what was consistent with Islam in Indonesia society and what was not, became clearer".

Bagi Muhammadiyah, organisasi yang bercorak modernis hanyalah jembatan, sarana atau wadah saja untuk mengaktualkan kepentingan umat Islam. Organisasi merupakan kendaraan yang membawa cita-cita umat kepada tujuannya tanpa terikat oleh mitologi perorangan. Muhammadiyah sebenarnya bukan gerakan pemberontakan budaya, namun sayang orang lebih banyak mengenal Muhammadiyah sebagai gerakan ganyang TBC (TahayulBid'ah-Churafat). Kekeringan budaya sebagai akibat sifat Muhammadiyah yang anti pati terhadap budaya lokal menjadikan organisasi ini tampak tidak berpijak pada realitas budaya. Kuntowijoyo menyebut gerakan ini sebagai "gerakan kebudayaan tanpa kebudayaan" (Mulkhan, 2000: x) atau gerakan puritanisme yang anti symbol (Shihab: 1998: 64). Mulkhan (1990: 73-83) berpendapat bahwa pemberontakan budaya tanpa suatu strategi sosial malah akan menghancurkan sisa-sisa potensi lama yang mungkin dapat digunakan untuk pembaruan. Sebaiknya Muhammadiyah bisa arif dalam memandang ekspresi budaya asal niatnya benar dan masih dalam koridor akhlak terpuji, yakni ekspresi yang tumbuh pada sumbu ibadah, tasbih, tazkiyah, shadaqah, sekedar ekspresi, sekedar impresi, atau mencari nafkah. Di sinilah Muhammadiyah agaknya perlu ijtihad dalam menyikapi simbolsimbol budaya tersebut (Shihab, 1998: 68).

Akan sangat paradoks ketika Muhammadiyah disebut sebagai organisasi modern namun memiliki kultur yang kaku dan rigid terhadap realitas sosial-budaya kekinian. Karena modernitas itu sendiri mestilah membuang watak a-demokratis dan a-sosial dalam bertindak dan meniscayakan adanya keterbukaan. Pada saat sekarang ini dimana organisasi tradisional telah mampu mengadopsi kultur modern, agaknya sudah tidak relevan lagi jika kita masih mengidap penyakit labeling, yakni melabelkan diri sebagai yang terbaik dan selalu menyatakan kelompok lain sebagai kelompok yang selalu salah. Sejatinya organisasi modern, seperti Muhammadiyah, dituntut untuk mampu menghargai dan menjalin kerjasama dengan siapapun sebagai refleksi perilaku modern (Saeed, 1994: 17) melihat bahwa masyarakat yang beranjak 
pada stadium modern harus memiliki modernisasi perilaku (attitudinal modernization) yang didukung oleh keberadaan individu-individu yang modern (modern individuals) dalam sebuah masyarakat. Ciri utama modernisasi perilaku ini adalah keterbukaan terhadap pengalaman-pengalaman baru dan kemauan untuk berubah.

\section{Kendala Dakwah Kultural}

Disadari atau tidak, dalam perkembangannya, Muhammadiyah terjebak dalam dua penyakit utama, yakni elitisme dan fiqihisme. Elitisme berarti bahwa Muhammadiyah masih merupakan organisasi kaum bourgeois yang belum mengakar dan diterima oleh kalangan masyarakat luas (Shihab, 1998: xxix). Elitisme pun terlihat pada sikap dan perilaku sebagian anggotanya yang sok priyayi dan enggan bergaul dengan masyarakat tempatan baik secara kultural maupun sosial. Alih-alih merangkul hati masyarakat melalui organisasi ini, Muhammadiyah dapat dipandang sebagai gerakan nyleneh yang salah mangsa karena perilaku segelintir Muhammadiyahis yang tidak luwes dan akomodatif. Elitisme dalam Muhammadiyah lebih diakibatkan oleh business-oriented dalam amal usahanya, sehingga pelayanan masyarakat yang dilakukan Muhammadiyah terkesan hanya untuk masyarakat menengah ke atas, semisal pelayanan pendidikan dan kesehatan yang susah dijangkau masyarakat awam (Mulkhan, 1990: 41).

"Gerakan Muhammadiyah saat ini dinilai sedang mengalami deviasi dari gerakan pencerahan budaya menjadi gerakan penegakan syariah yang elitis. Gerakan Salafi, seperti Muhammadiyah, memang dikenal sebagai gerakan non kompromi terhadap kondisi awal. Namun, karena perkembangan masyarakat yang sangat kompleks, maka Muhammadiyahpun harus memahami strategi perubahan yang humanis-kultural. Tidak heran jika selama ini Muhammadiyah kemudian berbenturan dan dikenal tidak toleran terhadap tradisi lokal. melontarkan kritik terhadap Muhammadiyah yang dipandangnya mengidap penyakit idiosyncrasy atau particularité sehingga terkesan sebagai organisasi yang kaku. Kekakuan ini karena Muhammadiyah sering terjebak pada polemik yang bermuara pada masalah furu'iyah dan fiqhiyah. Walhasil, Muhammadiyah sering pula terkungkung dalam terali fiqihisme yang dipenuhi polemik yang elitis dan eksklusif 
(Arifin, 2000: 71-80). Umat Islam masih selalu terjebak pada masalah nilai dan hubungan makna dalam masalah-masalah normatif. Justru hal-hal fungsional yang menyentuh masyarakat banyak tidak menjadi perhatian yang sepenuhnya”.

Di samping itu, modernisasi pendidikan dalam Muhammadiyah juga turut berkontribusi terhadap semakin langkanya kader Muhammadiyah yang mampu membaca "kitab kuning" (dengan bahasa Arabnya), dan pada saat yang bersamaan semakin berkurangnya kader yang mampu membaca "kitab putih" (dengan bahasa Inggrisnya) sebagai media memahami IPTEK (Mulkhan, 1990: 73). Sehingga para Muhammadiyahis muda akan menemui kesulitan ketika harus menyelami kitab-kitab klasik khasanah intelektual peradaban Islam sekaligus "menjenguk" jendela dunia yang mengglobal. Seharusnya melalui penguasaan diskursus kitab kuning ini dan kitab putih ini, Muhammadiyahis muda akan mampu mengembangkan kultur dialog yang merangkul banyak golongan. Mereka akan mampu menjadi warna dan jiwa dalam lapisan masyarakat manapun tanpa harus menampakkan aura mriyayeni.

Perlu diingat bahwa KH. Ahmad Dahlan pun pernah mengenyam pendidikan pesantren tradisional. Jika kita amati sejarah hidupnya, maka akan kita ketahui bahwa perjalanan intelektualnya tidak lepas dari jalur pendidikan tradisional pesantren sebagai pijakan awal. Bersama dengan $\mathrm{KH}$. Hasyim Asy'ari (1871-1947), ia berguru dengan seorang tokoh bernama Syeikh Ahmad Khatib al Minangkabawi di Mekah. KH. Ahmad Dahlan juga pernah belajar pada KH. Abdul Hamid di pesantren Lempuyangan, Yogyakarta, dan belajar di pesantren Tremas pada Kiai R. Haji Dahlan. Tokoh lain yang memiliki kultur pesantren lainnya adalah KH. Mas Mansur. Sewaktu berusia 10 tahun, KH. Mas Mansur dikirim belajar kepada Kiai Kholil Bangkalan, Madura, dan dua tahun kemudian dia tinggal di Mekah untuk memperdalam ilmu agama (Soebagjo: 1982: 77). Diyakini atau tidak, pesantren, sebagai institusi awal yang turut mendidik para pioner gerakan Muhammadiyah, telah melakukan peran instrumental dalam mencetak kader ulama. Maka sangat tidak bijaksana bagi kalangan muda Muhammadiyah 
untuk menafikan peran pesantren dalam pribadi para founding fathers-nya (Azra, 1999: 26).

\section{Simpulan}

Menatap kembali Muhammadiyah saat ini tentunya harus dibedakan ketika kita menengok Muhammadiyah dalam konteks sejarah masa lalu. Semangat Muhammadiyah masa lalu hendaknya harus dipelihara oleh para Muhammadiyahis muda dalam menghidup-hidupkan Muhammadiyah agar sesuai dengan konteks dan tuntutan zaman. Melalui dakwah cultural, maka potensi dan sumber daya yang dimiliki masyarakat Islam dapat dimanfaatkan sebagai modal untuk membangun umat ke depan. Kuntowijoyo berpendapat bahwa Muhammadiyah harus bisa menjadi rahmatan lil'alamin. Hal ini berarti bahwa Muhammadiyah harus memiliki kemampuan untuk dapat ada di tengah bermacamnya suku, ras, agama, budaya, kelas sosial, dan berbagai profesi sebagai sebuah kenyataan objektif yang tak terelakkan (Shihab, 1998: xxix). Dengan demikian Muhammadiyah akan mampu lebih kritis dan dewasa memahami bangunan masyarakat dari berbagai sisinya. Oleh karena itu untuk melaksanakan dakwah kultural ini, proses fungsionalisasi dengan landasan rasionalisasi terhadap pesan-pesan agama dan realitas sosial merupakan sebuah keniscayaan. Muhammadiyah dapat dipandang sebagai a guardian of pristine Islam (pemelihara Islam yang murni). Karena kemampuannya untuk menerjemahkan Islam dalam konteks kemodernan tanpa melukar prinsip utama teologi Islam (Azra, 2000: 11-18).

Di samping itu, Muhammadiyah terbukti mampu memisahkan antara kepentingan politik dan organisasi (political disengagement) meskipun diakui bahwa organisasi ini membutuhkan saluran politik untuk menyuarakan perjuangannya pada tataran yang lebih luas. Kondisi inilah yang membedakan pola perjuangan $\mathrm{KH}$ Ahmad Dahlan dengan tokoh-tokoh salaf dunia semacam Syah Waliullah, Muhammad ibn Abdul Wahab, Hasan al Bana, Sayyid Quthb, dan Almawdudi. Keengganan Muhammadiyah untuk terlibat dalam politik praktis adalah untuk menghindari langkah konfrontatif dan emosional di samping pada saat 
itu sudah terlalu banyak organisasi-organisasi lain yang berkecimpung dalam arena politik (Jainuri, 1981: 01).

Sejalan dengan pemikiran non politis Muhammadiyah ini bahwa Islam merupakan sistem budaya yang rentan terhadap agenda politisasi; politisasi hanyalah akan menghancurkan Muslim dan peradaban lainnya. Akibat yang muncul karena politisasi adalah ide Islamisme yang mengatasnamakan Islam untuk kepentingan pihak-pihak tertentu (Tibi, 2001: 1). Mungkin sejak jauh-jauh hari Muhammadiyah menyadari betapa dakwah akan menjadi ajang provokasi dan makelar fragmentasi sosial jika sudah diseret ke arena politis. Bagaimanapun ke depan, Muhammadiyah dituntut untuk lebih arif dan bijaksana dalam menelisik diri dan berusaha untuk melebarkan sayap organisasi melalui dialog dan dakwah kultural baik bi al lisaan (tekstual-teoritis) maupun bi alhaal (kontekstual-riil) tanpa harus mencabuti akar potensi masyarakat mad'u. Sehingga Muhammadiyah disamping dipandang sebagai organisasi pembaruan, diapun akan dipandang sebagai pionir organisasi pembauran.

\section{Daftar Pustaka}

Azra, Azyumardi. 1999. Esei-Esei Intelektual Muslim dan Pendidikan Islam. Jakarta: Logos.

Ali, A. Mukti. 1971. Alam Pikiran Modern di Indonesia. Yogyakarta: Nida.

Abaza, Mona. 1994. Islamic Education: Perceptions and Exchanges Indonesian Students in Cairo. Paris: Association Archipel.

Abduh, Muhammad. 1966. The Theology of Unity, Ishaq Musaad dan Kenneth Cragg (trans). London: George Allen \& Uwin.

Arifin, Syamsul. 2000. Muhammadiyah, Akomodasi Kultural dan Penguatan Pluralitas, dalam Edy Suandi

Beyer, Peter. 1994. Religion and Globalization. London: SAGE Pub.

Benda, Harry J. 1958. The Crescent and the Rising Sun: Indonesian Islam Under 
the Japanese Occupation 1942- 1945 The Hague: W. van Hoeve.

Choudhury, Golam W. 1993. Islam and the Modern Muslim World. England: Scorpion Publishing Ltd.

Damami, Mohammad. 2000. Akar Gerakan Muhammadiya. Yogyakarta: Fajar Pustaka.

Esposito, John L. 1998. Islam the Straight Part. Oxford. Oxford University Press.

Hadikusuma, Djarnawi. tt. Aliran Pembaruan dalam Islam dari Jamaluddin AlAfghani sampai KH Ahmad Dahlan. Yogyakarta: Persatuan

Huntington, Samuel. 1996. Clash of Civilization and the Remaking of World Order. New York: Simon and Schuster.

Jainuri, Ahmad. 1981. Muhammadiyah: Gerakan Reformasi Islam di Jawa pada Awal Abad kedua Puluh. Surabaya: PT Bina Ilmu.

Mulkhan, Abdul Munir. 1990a. Pemikiran KH Ahmad Dahlan dan Muhammadiyah dalam Perspektif Perubahan Sosial. Jakarta: Bumi Aksara.

Nakamura, Mitsuo. 1983. The Crescent Arises Over the Banyan Tree.Yogyakarta: Gadjah Mada University Press.

Noer, Deliar. 1973. The Modernist Muslim Movement in Indonesia 1900-1942. Singapore: Oxford University Press.

Osman, Mohd Taib (ed). 1997. Islamic Civilization in the Malay World. Selangor Darul Ehsan: Sasyaz Holdings Sdn. Bhd.

Peacock, James L. 1978. Muslim Puritans: Reformist Psychology in Southeast Asian Islam. London: University of California Press.

QS. Al Hujurat (49): 11.

QS. Alhujurat (49): 12.

QS. Ali Imron (3): 84. 
Shihab, Alwi. 1998. Membendung Arus: Respon Gerakan Muhammadiyah terhadap Penetrasi Misi Kristen di Indonesia. Bandung: Mizan.

Starrett, Gregory. 1998. Putting Islam to Work: Education, Politics, and Religious Transformation in Egypt, London: University of California Press.

Saeed, Javaid. 1994. Islam and Modernization: A Comparative Analysis of Pakistan, Egypt, and Turkey. London: Praeger Publisher.

Soebagjo I.N. 1982. KH Mas Mansur: Pembaharu Islam di Indonesia. Jakarta: Gunung Agung.

Tibi, Hasan. 2001. Islam between Culture and Politics. New York: Palgrave.

Weber, Max. 1958. The Protestant Ethic and the Spirit of Capitalism. Talcot Parson (trans). New York: Scribner. 